\title{
From the Editor of Sexuality and Disability: The International Political Climate Highlights Even More the Importance of Awareness, Education, Respect and Working Together to Address Sexuality and Disability
}

\section{Sigmund Hough ${ }^{1}$}

Published online: 2 February 2017

(C) Springer Science+Business Media New York 2017

The journal of Sexuality and Disability remains a professional home for many, and a place of professional rejuvenation and professional exploration for still more. If you are new to the journal, we offer to you a "BIG WELCOME" to participate as a reader, author, academician, clinician, educator, service provider, researcher, advocate, and individual or individuals seeking information. Over decades of contribution to the literature on sexuality and disability, we have been a part of the growth and understanding. Now most importantly, we continue to be a part of change in how we look and examine the topic, the need, and the response in terms of best practice- evidence based approaches. With the intelligence, experience, motivation and commitment from our authors, readership, peer reviewers and editorial board, and resources with guidance from the Springer Staff, our journal's mission continues to be strong and meaningful.

The journal Sexuality and Disability continues to provide original impact articles addressing the mental health and medical aspects of sexuality in relation to rehabilitation, hospital, academic and community settings, publishing up-to-date articles, case studies, clinical practice reports, reviews, featured articles, historical articles, special grand rounds topics, brief research reports and survey data reports. Value benefit is provided to authors through worldwide electronic exposure and professional access, while readership gains from scholarly contributions to advance the field through research, best-practice and educational articles. The refined lens of individual contributions from the local and international community continues to deliver a wealth of information on the topic of sexuality and disability for the reader. Thank you for joining our community.

New beginnings are built upon the past. As we begin 2017, we give appreciation to the current and past Editorial Board Members, Reviewers and Authors for their specific dedication to the field of sexuality and disability. Such efforts provide solid foundation.

New Beginnings are built upon the present. As we begin 2017, we give appreciation to Springer and Staff for providing a consistent high powered respectful academic forum.

Sigmund Hough

Sigmund_Hough@hms.harvard.edu

1100 Cummings Center, Suite 207, Beverly, MA 01915-6144, USA 
Such efforts provide a dynamic sharing of health care knowledge and intellectual curiosity for a strong international community.

New Beginnings are built upon motivation to continue, investment in addressing the needs of others, and commitment to oneself to sustain the drive to find answers. Most important, solutions and ways to make things better.

As you read this 2017 issue of the journal Sexuality and Disability, we give appreciation for the opportunity to have a voice to share, and to have continued future New Beginnings. 